\title{
LA DEFERENCIA AL LEGISLADOR EN MATERIA IMPOSITIVA: ANÁLISIS CRÍTICO DEL FALLO GARCÍA DE LA CORTE SUPREMA ARGENTINA'
}

\section{The deference to the legislature in tax law: critical analysis to the sentence García from the Supreme Court of Justice of the Argentine Nation}

\author{
ALEJO JOAQUÍN GILES² \\ Universidad Nacional de La Plata \\ alejoigiles@gmail.com
}

Cómo citar/Citation

Giles, A. J. (2020)

La deferencia al legislador en materia impositiva: análisis crítico del fallo García de la Corte Suprema argentina. Anuario Iberoamericano de Justicia Constitucional, 24(2), 465-492. doi: https://doi.org/10.18042/cepc/aijc.24.15

\section{Resumen}

En este trabajo me propongo analizar la sentencia dictada por la Corte Suprema de Justicia de la Nación Argentina en el caso García de mayo de 2019. La cuestión resuelta y las posturas asumidas por los votos que la componen la vuelven conceptualmente rica. La mayoría del tribunal declaró la inconstitucionalidad de la legislación

\footnotetext{
Agradezco a Isabel Lifante Vidal (U. de Alicante) sus comentarios, que orientaron y enriquecieron el presente trabajo. El trabajo se ha beneficiado también de las sugerencias de dos evaluaciones anónimas remitidas por el consejo de redacción del Anuario.

2 Abogado graduado en la Universidad Nacional de La Plata. Doctorando en Filosofía del Derecho (U. de Génova). Máster en Argumentación Jurídica (U. de Alicante) y en Razonamiento Probatorio (U. de Girona y U. de Génova). Contacto: alejojgiles@ gmail.com, unlp.academia.edu/ajgiles.
} 
impositiva impugnada a través de la cuestionable aplicación al caso del principio de igualdad, que - como argumentaré - falla en la demostración de su razonabilidad y en su anclaje con las circunstancias del caso bajo estudio. El voto disidente adoptó una postura deferente al legislador que parece la más aceptable pero apoyándose en razones que, generalizadas, podrían resultar problemáticas para el control de constitucionalidad y, en todo caso, requerirían de un ejercicio más acabado de argumentación. A continuación presentaré una sistematización y un análisis crítico de los argumentos presentados en ambos votos.

\section{Palabras clave} lismo.

Igualdad; razonabilidad; deferencia al legislador; legislación impositiva; forma-

\section{Abstract}

In this paper I aim to analyze the sentence ruled by the Supreme Court of Justice of the Argentine Nation in "García» on May, 2019. The matter ruled and the points of view adopted by te votes make it conceptually rich. The majority declared the unconstitutionality of the impugn tax legislation through the questionable application to the case of the principle of equality, that - as I will argue - fails to demonstrate its reasonability and its anchorage with the circumstances of the case under study. The dissenting vote took a deferential position to the legislator that seems the most acceptable but based on reasons that, generalized, could be problematic for the control of constitutionality and, in any case, would require a more finished exercise of argumentation. At once I will present a systematization and a critical analysis of the arguments presented in both votes.

\section{Keywords}

Equality; reasonability; deference to the legislature; tax law; formalism. 


\section{SUMARIO}

I. INTRODUCCIÓN. II. LA CUESTIÓN JURÍDICA A RESOLVER Y ALGUNOS DATOS DE CONTEXTO. III. LOS ARGUMENTOS DE LA SENTENCIA: DOS VOTOS ENFRENTADOS: 1. El voto de la mayoría: la inconstitucionalidad. 2. El voto disidente: la constitucionalidad. IV. ANÁLISIS CRÍTICO DE LOS ARGUMENTOS DE LA SENTENCIA: 1. El voto mayoritario, la razonabilidad y la aplicación de generalizaciones. 2. El voto disidente y las razones para ser deferentes con el legislador. V. CONCLUSIONES. Bibliografía.

\section{INTRODUCCIÓN}

En este trabajo analizaré la sentencia dictada por la Corte Suprema de Justicia de la Nación Argentina en el auto García, M. I. cl AFIP s/ acción meramente declarativa de inconstitucionalidad el 26 de mayo de 2019 (Fallos: 342:411)3. En el caso la Corte resolvió una acción declarativa de inconstitucionalidad presentada por una persona jubilada contra la Administración Federal de Ingresos Públicos, el órgano estatal encargado de recaudar los tributos nacionales ${ }^{4}$.

La riqueza de la sentencia viene dada por las posiciones asumidas en ella por los magistrados del máximo tribunal argentino. En votos divididos, la mayoría acogió la demanda, declarando la inconstitucionalidad del pago del impuesto en el caso analizado, mientras que la disidencia resolvió el rechazo del planteo. La mayoría sostuvo que el precepto impugnado es irrazonable en tanto aplica a todos los jubilados el mismo criterio (el pago del impuesto para quienes superen cierta línea de base), sin distinguir entre categorías de

3 La sentencia puede consultarse en el portal web de la Secretaría de Jurisprudencia de la CSJN (sj.csjn.gov.ar/sj) seleccionando la opción «Búsqueda por cita de 'Fallos'» e introduciendo para "Tomo» y «Página» los números 342 y 411, respectivamente.

4 En el marco de las acciones declarativas del ordenamiento procesal nacional argentino, corresponde a los jueces «hacer cesar un estado de incertidumbre sobre la existencia, alcance o modalidades de una relación jurídica» (art. 322 del Código Procesal Civil y Comercial de la Nación). Cuando esa incertidumbre es generada por la validez constitucional de una ley, los jueces pueden declarar su inconstitucionalidad e inaplicarla para un caso concreto. 
jubilados (donde unos son más vulnerables que otros). La disidencia, en cambio, propuso el rechazo de la demanda, adoptando una postura deferente al Poder Legislativo.

En los argumentos interpretativos de ambos votos se encuentran aristas interesantes que propongo analizar. A nivel global me interesa echar luz sobre las posiciones que ambos votos adoptan sobre la interpretación jurídica y la función del Poder Judicial en esta clase de casos y sobre su proyección sobre otras materias. Se trata de una decisión relevante para la jurisprudencia del país, ya que delimita las atribuciones jurisdiccionales sobre las facultades del Congreso de imponer tributos. A la vez, la problemática que aborda resulta común para los Estados constitucionales y sigue suscitando debates en la academia y en los tribunales. Las posturas que se sostienen en esta sentencia del máximo tribunal argentino y las críticas a las que cada una de ellas está expuesta pueden servir en el ámbito iberoamericano para seguir reflexionando sobre las competencias y los límites de la justicia constitucional.

La metodología será la siguiente. Comenzaré con una descripción de la cuestión jurídica a resolver (II) y con una reconstrucción de los principales argumentos que presentan ambos votos pretendiendo reflejarlos con fidelidad (III). Luego presentaré un análisis crítico de ambos (IV). En esa última instancia se buscará mostrar las debilidades del voto mayoritario al momento de demostrar la irrazonabilidad de la norma cuestionada y su aplicación al caso objeto de decisión y los problemas que tiene la postura adoptada por la disidencia en tanto podría vaciar de contenido el control de razonabilidad de las leyes y, de ser generalizada a las otras materias distintas a la impositiva, convertirse en un alegato a favor del formalismo en la interpretación jurídica

\section{LA CUESTIÓN JURÍDICA A RESOLVER Y ALGUNOS DATOS DE CONTEXTO}

La cuestión a resolver en el caso era la siguiente: ¿ৃresulta constitucionalmente válido gravar con el Impuesto a las Ganancias a las rentas provenientes de la jubilación de la actora?

Dado el carácter difuso e inter partes del sistema de control de constitucionalidad argentino, los efectos de la sentencia se extienden exclusivamente sobre la situación de las partes de cada proceso. El sistema de control de constitucionalidad argentino es difuso en el sentido de que todos los jueces, federales o locales y cualquiera sea su jerarquía, pueden inaplicar una disposición normativa por ser contraria a la Constitución Nacional. Esa decisión es siempre inter partes, dado que rige únicamente para el caso concreto que se está resolviendo. Si bien no existe en Argentina un sistema de precedentes, la 
Corte tiene dicho que sus decisiones deben ser consideradas y seguidas por los tribunales inferiores cuando estos resuelvan casos sustancialmente análogos ${ }^{5}$.

La Ley de Impuesto a las Ganancias (n. ${ }^{\circ} 20.628$ ) incluye expresamente la clase de ingresos que nos ocupan como hechos imponibles del gravamen. Para la norma, todas las "ganancias" obtenidas por las personas humanas y jurídicas son objeto de tributo (art. 1), incluyendo en general «los rendimientos, rentas o enriquecimientos susceptibles de una periodicidad que implique la permanencia de la fuente que los produce y su habilitación» (art. 2, inciso 1). Dentro de esas rentas, el art. 79, inciso "C», de la ley incluye a las jubilaciones en los siguientes términos:

Constituyen ganancias de cuarta categoría las provenientes: [...] c) De las jubilaciones, pensiones, retiros o subsidios de cualquier especie en cuanto tengan su origen en el trabajo personal y en la medida que hayan estado sujeto al pago del impuesto, y de los consejeros de las sociedades cooperativas.

La parte accionante cuestionó la validez constitucional de esas disposiciones y los tribunales que intervinieron en su caso le dieron la razón ${ }^{6}$. La Cámara Federal de Apelaciones de Paraná, que fue el último tribunal en resolver antes del dictado de la sentencia bajo comentario, se apoyó en tres motivos: que la jubilación no puede ser considerada una "ganancia», que la imposición tributaria sobre la misma viola su «integralidad» e implica una doble imposición. Esa resolución fue recurrida por el órgano demandado ante la Corte Suprema de Justicia de la Nación, alegando la validez constitucional de la norma federal impugnada. La Corte es, dentro de la organización de justicia argentina, el último intérprete de la Constitución Nacional y de las leyes federales, es decir, las dictadas por el Congreso de la Nación ejerciendo alguna de las competencias que las provincias le delegaron en el art. 75 del texto constitucional.

Entre la sentencia de la Cámara y la definitiva de la Corte Suprema se sancionó, a fines del año 2016, la ley n. ${ }^{\circ}$ 27.346, que modificó parte del contexto jurídico del caso. Entre otras reformas sobre el gravamen que nos ocupa, incorporó un supuesto de deducción especial a favor de los sujetos

5 Véase la sentencia dictada en Viñas, Pablo c/ EN - M Justicia y DDHH, Fallos: 341:570, del 22 de mayo de 2018.

$6 \mathrm{Al}$ ser normas federales y dirigirse la demanda contra un órgano de la Administración Pública Nacional intervino la justicia federal con competencia contencioso administrativa, integrada por jueces de primera instancia con asiento en distintos puntos del territorio y una serie de cámaras de apelaciones colocadas en las principales ciudades del país. Las resoluciones adoptadas por esas cámaras pueden ser recurridas únicamente ante la Corte Suprema de Justicia de la Nación. 
alcanzados por las rentas gravadas en el art. 73 inciso «C» (jubilados, pensionados, retirados o subsidiados): podrán deducir el equivalente a seis veces la suma de los «haberes mínimos garantizados» ${ }^{7}$. La reforma implica que, dentro del universo de jubilados y pensionados del Sistema Integrado Previsional Argentino, solo deberían tributar en las actuales circunstancias socio-económicas un $10 \%$ de los agentes, el decil que más altas prestaciones recibe.

El Impuesto a las Ganancias tiene un peso relevante en la recaudación tributaria nacional y en el gasto en Seguridad Social. En el año 2018 las arcas del Estado nacional se conformaron en un $67,7 \%$ por ingresos impositivos, en un $34,8 \%$ por aportes a la Seguridad Social y en un 7,4\% por recursos aduaneros. Dentro de los impuestos, los que más recursos proporcionaron son el Impuesto al Valor Agregado (con el 48,1\%) y el Impuesto a las Ganancias (con el 32,3\%). Sobre el total de ingresos tributarios nacionales, Ganancias aportó casi un $22 \%{ }^{8}$. De esos recursos se nutre en parte la Seguridad Social. En el año 2017 la Administración Nacional de la Seguridad Social recibió un 60,7\% de sus ingresos de los aportes y contribuciones de empleadores y trabajadores y un $27,8 \%$ de recursos tributarios. Un 40,2\% de recursos tributarios provinieron del Impuesto a las Ganancias (lo que significa un 11,2\% del total de los ingresos del órgano que paga jubilaciones y pensiones) ${ }^{9}$.

La sentencia que se analizará se enmarca en el contexto de otras decisiones de la Corte Suprema con impacto en el sistema previsional. El 18 de diciembre de 2018 el tribunal dictó sentencia en la causa «Blanco, L. O. cl ANSeS s/ reajustes varios» (Fallos: 341:1924), donde se discutía qué índice correspondía aplicar al cálculo del haber previsional. La Administración pública pretendía aplicar el RIPTE, que refleja la remuneración imponible promedio de los trabajadores estables. La Corte, en cambio, dispuso que se aplique el ISBIC hasta que el Congreso legisle sobre el asunto, es decir, el índice de salarios básico de la industria y la construcción. Este último arroja, se estima, un haber entre un $30 \%$ y un $60 \%$ más elevado. Si bien los alcances de la sentencia son inter partes, es probable que el criterio sea

7 El art. 23 de la Ley de Impuesto a las Ganancias prevé en general tres supuestos de deducción: (a) ganancias no imponibles hasta 51.967 pesos argentinos; (b) cargas de familia (por cónyuge e hijos a cargo); y (c) por rentas de tercera categoría hasta 51.967 pesos argentinos. Para los jubilados, pensionados, retirados o subsidiados la Ley 27.346 incorporó, en reemplazo, la deducción especial mencionada: seis veces los «haberes mínimos garantizados», cuyo valor desde marzo de 2019 es de 10.410 pesos argentinos (res. 74/2019 de la ANSES). La deducción especial, entonces, se aplica actualmente a ingresos de hasta 62.460 pesos argentinos. Pagan Ganancias quienes perciben más de eso.

8 Datos obtenidos de afip.gob.ar/institucional/estudios/ (último acceso: noviembre de 2019).

9 Datos obtenidos de anses.gob.ar/informacion/datos-abiertos-financiero (último acceso: noviembre de 2019). 
replicado por el propio tribunal y por los tribunales inferiores en los miles de casos similares que se encuentran en trámite ${ }^{10}$.

\section{LOS ARGUMENTOS DE LA SENTENCIA: DOS VOTOS ENFRENTADOS}

En ese contexto, la Corte tenía para resolver, entre cientos de impugnaciones similares, un recurso extraordinario presentado por la Administración Federal de Ingresos Públicos contra la sentencia que declaró a favor de la parte actora la inconstitucionalidad de la deducción del Impuesto a las Ganancias sobre las rentas provenientes de su jubilación. La decisión del máximo tribunal federal se bifurcó en dos votos enfrentados cuyos principales argumentos reconstruiré a continuación.

\section{EL VOTO DE LA MAYORÍA: LA INCONSTITUCIONALIDAD}

A la cuestión central a resolver la mayoría responde que no: según ella no es constitucionalmente válido gravar con el Impuesto a las Ganancias a los ingresos provenientes de la jubilación de la accionante.

La línea argumentativa más importante de la decisión, en la que pondré el foco, consiste en lo que podríamos llamar una extensión (o precisión) de los alcances del principio de igualdad y no discriminación sobre el terreno tributario. Sintetizadas, sus premisas son las siguientes: al tratar igual a los desiguales se viola el principio de igualdad; al realizar categorizaciones el legislador debe dar un trato especial a los sujetos en condición de vulnerabilidad. En el caso, el legislador, si bien distinguió a los efectos del pago del tributo entre trabajadores activos y personas jubiladas, no recabó que en esta última categoría existen personas más vulnerables que otras, por lo que ha incurrido en una «subcategorización».

Como primer paso se señala que la Ley de Impuesto a las Ganancias, con la reforma de 2016, distingue para lo que nos ocupa entre dos categorías: los trabajadores activos y los jubilados, pensionados, retirados o subsidiados, otorgándoles a estos últimos una escala de deducciones más beneficiosa. Asume la norma que es un "colectivo uniforme», que todos sus integrantes están en las mismas circunstancias. Sin embargo, afirma el voto, existen condiciones especiales que permitirían hacer distinciones: producto de la avanzada edad o de otras situaciones particulares como la discapacidad, dentro de esa categoría algunos tienen una mayor vulnerabilidad que otros.

10 Según surge del sistema de consultas de la Corte, el fallo Blanco fue citado en $273 \mathrm{fa}$ llos por el propio tribunal, muchos de los cuales resuelven — con esa referencia- más de un recurso a la vez. 
De ese modo entra en escena el principio de igualdad.

Sostiene la mayoría que en materia impositiva el principio de igualdad no solo exige la creación de categorías tributarias razonables, "sino que también prohíbe la posibilidad de unificar las consecuencias tributarias para situaciones que en realidad son distintas» (cdo. 10). Para ese criterio, «es tan injusto gravar en distinta forma a quienes tienen iguales medios como imponer la misma contribución a quienes están en desigual situación» (cdo. 10). Si bien el Poder Legislativo detenta una amplia libertad para ordenar, agrupar, distinguir y clasificar los objetos de la legislación:

[...] el establecimiento de categorías para la percepción de los impuestos debe ser estrictamente compatible con el principio de igualdad, no solo a condición de que todos los que sean colocados en una clase o categoría reciban el mismo trato [citas omitidas], sino también —y es lo esencial— que la clasificación misma tenga razón de ser, esto es que corresponda razonablemente a distinciones reales (cdo. 10).

A eso se agrega, entre los cdos. 11 y 15, que, cuando se trata de sectores vulnerables como el de los jubilados, el legislador debe dar respuestas especiales y diferenciadas que aseguren el goce pleno y efectivo de sus derechos. Tal imperativo es transversal a todo el ordenamiento jurídico y aplica también a la materia fiscal: el sistema tributario no es un comportamiento estanco y autosuficiente; debe respetar la Constitución.

Trazado ese panorama se agrega una premisa clave para el razonamiento, según la cual el envejecimiento y la discapacidad, fenómenos por los cuales se accede al estatus de jubilado, son causas predisponentes o determinantes de vulnerabilidad, "circunstancia que normalmente obliga a los concernidos a contar con mayores recursos para no ver comprometida seriamente su existencia y/o calidad de vida y el consecuente ejercicio de sus derechos fundamentales» (cdo. 13).

Y luego se da un segundo paso, sosteniendo que la falta de consideración de la vulnerabilidad vital del colectivo concernido como pauta de diferenciación "pone igualar a los vulnerables con quienes no lo son, desconociendo la incidencia económica que la carga fiscal general en la formulación del presupuesto de gastos que la fragilidad irroga» (cdo. 17).

Es insuficiente, se afirma, tomar como parámetro para el establecimiento de tributos a jubilados, pensionados, retirados o subsidiados su sola capacidad contributiva, por el «hecho evidente de que el mismo ingreso no impactará de igual manera en un caso que en otro, insumiendo más gastos en el primero que en el segundo» (cdo. 18). Allí es donde aparece el concepto de "subcategorización»: el criterio estrictamente patrimonial utilizado por el legislador —la fijación de un mínimo no imponible — termina por subcategorizar «a un universo de contribuyentes que, de acuerdo a una realidad que la Constitución obliga a considerar, se presenta heterogéneo» (cdo. 18). 
Poniendo el foco en las circunstancias de la demandante, el voto mayoritario da cuenta de tres factores que considera probados en la causa: que al deducir la demanda la actora tenía 79 años, que padecía «problemas de salud» y que el fisco nacional le venía descontando alrededor del $30 \%$ de sus ingresos como jubilada. Tales circunstancias, afirma, "convierten a la tipología originaria del legislador, carente de matices, en una manifestación estatal incoherente e irrazonable, violatoria de la Constitución Nacional» (cdo. 19). Hace falta, sugiere el voto, una "percepción fina" que incorpore a la capacidad económica elementos que den cuenta de la vulnerabilidad del sujeto.

En virtud de lo señalado se concluye que en el caso la percepción del tributo sobre la jubilación de la actora es inconstitucional. Como reparación, se ordena devolver a la actora los montos que en ese concepto se hubieran percibido y la abstención de continuar reteniéndole el impuesto hasta que el Congreso Nacional legisle al respecto, es decir, cese en su «omisión de disponer un tratamiento diferenciado para aquellos beneficiarios en situación de mayor vulnerabilidad que se encuentran afectados por el tributo (en especial los más ancianos, enfermos y discapacitados)» (cdo. 23).

El criterio adoptado en este caso fue replicado recientemente, con remisión al mismo, en otros casos. Entre mayo y septiembre de 2019 la Corte dictó 12 fallos en donde resolvió conjuntamente un total de 112 recursos extraordinarios a los que aplicó el precedente García, entendiendo que este respondía a las cuestiones planteadas en esas vías recursivas. La mayoría de esos expedientes provenían de la Cámara Federal de Paraná, que venía adoptando el criterio que replicó en el caso que aquí se comenta ${ }^{11}$.

Luego del fallo García se presentaron en el Congreso varios proyectos de reforma a la Ley de Impuesto a las Ganancias. Unos proponen una exención a las «personas mayores de 80 años o que sean menores de esa edad pero estén gravemente enfermas» (expediente 1195-D-2019), mientras que otros bregan por una exención general a las ganancias originadas por jubilaciones y pensiones (expedientes 1205-D-2019, 1213-D-2019, 1228-D-2019, 1234-D-2019, 837-S-19, 842-S-19, 929-S-19, 1019-S-19,1073-S-19). En el diálogo institucional, hasta ahora los legisladores han procesado de ese modo el mensaje.

\section{EL VOTO DISIDENTE: LA CONSTITUCIONALIDAD}

En su voto disidente el juez Rosenkrantz entendió que resulta perfectamente válido a nivel constitucional gravar con el impuesto las rentas provenientes de la jubilación de la actora.

11 Esta información puede consultarse en el portal web de la Secretaría de Jurisprudencia de la CSJN (sj.csjn.gov.ar/sj), buscando la sentencia objeto de comentario y consultando, en el anexo documental, la sección «Citan este fallo». 
El mayor peso argumentativo del voto está puesto en remarcar el interés general de la imposición del tributo y la función excluyente del Congreso en la distribución de la riqueza nacional, de acuerdo con criterios de justicia social y articulando los derechos y objetivos sociales reconocidos en el ordenamiento jurídico. Eso hace, en la mirada de Rosenkrantz, que los jueces deban adoptar una posición deferente a las preferencias expresadas por los representantes del pueblo en materias como las que nos ocupan.

El punto de partida de esa línea argumentativa es la siguiente premisa: «el Congreso de la Nación es el órgano donde encuentran su representación natural las diversas opiniones, valores, convicciones y preferencias sostenidas por el pueblo de la Nación» (cdo. 5). Por eso tiene la función de «articular los muchos derechos y objetivos sociales que deben ser honrados en la regulación del sistema de seguridad social del país» (cdo. 5). Al Poder Judicial, en cambio, le compete evaluar si esa atribución ha sido ejercida razonablemente, sin desnaturalizar los derechos reconocidos en el texto constitucional. Esa función del Congreso, agrega, «es interdependiente de otros cometidos igualmente exigidos por la norma constitucional que también requieren la imposición de cargas y la asignación de recursos a distintos individuos o sectores de la sociedad» (cdo. 6). Al no poder satisfacerse en aislamiento de otros objetivos, el deber de garantizar la seguridad social debe llevarse adelante "guiado por una concepción de la justicia distributiva o justicia social» (cdo. 6).

Por eso mismo, se afirma seguidamente, la evaluación de la constitucionalidad de las medidas legislativas que aspiran a realizar dicho mandato de justicia distributiva en el sistema jubilatorio, «no puede llevarse a cabo sino teniendo en cuenta el modo en que los órganos representativos de la voluntad popular han decidido que aquel sistema se financie» (cdo. 7). En la distribución de competencias impuesta por la Constitución, al Congreso le toca un rol preponderante: por representar la voluntad popular, es allí donde se deben adoptar las normas que estructuran la concepción de la justicia distributiva que dicho texto ordena realizar. Ante ello, el Poder Judicial debe ser «especialmente prudente al analizar la concreción de las mandas constitucionales por parte del órgano deliberativo diseñado para consensuar el modo en que los diversos componentes de una solución distributivamente justa se articulan» (cdo. 7).

Gravar las jubilaciones más elevadas, como lo hace el sistema impositivo argentino desde la reforma de 2016, no responde a una política socialmente regresiva. Por otro lado, dado que el régimen impositivo depende de múltiples valoraciones, hechos, estrategias y criterios de oportunidad cuya articulación corresponde primariamente al Congreso de la Nación, el hecho de que los jueces consideren que el Estado no ha hecho lo que ellos desearían no puede convertirse en un argumento para declararlo inconstitucional; "las razones que nos convencen a cada uno de nosotros no se convierten, por ello, en derecho vigente» (cdo. 19, último párrafo). 
En nuestra democracia constitucional, afirma el voto, es el Congreso el órgano que debe, dentro de los amplios límites que la Constitución le fija, "tomar las medidas necesarias para, en última instancia, concretar los mandatos de promover el bienestar general y realizar la justicia distributiva» (cdo. 20). Eso se traduce, en materia tributaria, en la libertad de establecer las clasificaciones que considere pertinentes. Si bien el Poder Judicial está facultado para pronunciarse sobre la constitucionalidad de las normas tributarias, «no son los jueces quienes están llamados a concretar sus concepciones de la justicia distributiva o social, por valiosas o defendibles que ellas fuesen, a través del desarrollo interpretativo de principios o valores generales contenidos en las normas bajo análisis» (cdo. 20). El Poder Judicial no se encuentra facultado para establecer categorías tributarias o distinciones no previstas en las leyes, solo le corresponde declarar si las mismas repugnan o no los principios contenidos en la Constitución.

El juez aclara, por otra parte, que los tratados internacionales a los que la reforma de 1994 dio jerarquía constitucional «no constituyen fuente de un derecho constitucional a que las jubilaciones estén exentas del impuesto a las ganancias». Si bien mencionan el derecho a la Seguridad Social, no disponen expresamente que las jubilaciones no puedan ser gravadas. Tal como se encuentra consagrado en los tratados:

[...] el derecho a la seguridad social [...] no permite fundar una prohibición constitucional absoluta de gravar las jubilaciones y pensiones. No cabe inferir de las normas redactadas en el nivel de generalidad recién reseñado una restricción a la facultad constitucional expresa del Congreso de gravar ciertas manifestaciones de riqueza (cdo. 17).

El art. 73, inciso 23, de la Constitución, agrega, tampoco apoya la declaración de inconstitucionalidad buscada. Si bien coloca en cabeza del Congreso la función de adoptar medidas que garanticen la igualdad de oportunidades y el goce pleno de los derechos en particular respecto de los niños, las mujeres, los ancianos y las personas con discapacidad, «no exime a dichas personas, por esa sola circunstancia, de la obligación de pagar los tributos que el congreso establezca para afrontar los gastos del Estado» (cdo. 18, párr. 3). La actora podría ser considerada una persona "anciana», y justificar así ser beneficiada por medidas de acción positiva por parte del Estado, pero eso no le da derecho a no tributar.

En lo que hace a la situación de la accionante, la disidencia agrega información del expediente que no surge con claridad del voto mayoritario. Según relata, la causa fue declarada de puro derecho sin mayor actividad probatoria. La documentación acompañada solo acreditó la edad de la actora (79 años), el monto de sus haberes jubilatorios (que la colocan en el decil más acaudalado entre los jubilados), el aporte de alrededor de un 
$30 \%$ de esos haberes en concepto de Impuesto a las Ganancias y una serie de gastos que representan el $0,68 \%$ de sus ingresos. A eso se suman las manifestaciones de la propia actora (no acompañadas por evidencias) sobre que padecería problemas de salud (los «obvios y normales para la edad», según alegó). Según ese cuadro, la actora es de los jubilados que más cobran en el país, no indicó ni probó qué problemas de salud la aquejan ni cuáles serían los gastos a ellos asociados y tampoco produjo otra prueba relevante.

\section{ANÁLISIS CRÍTICO DE LOS ARGUMENTOS DE LA SENTENCIA}

En lo que sigue analizaré desde una perspectiva crítica los argumentos interpretativos de los votos bajo estudio.

\section{EL VOTO MAYORITARIO, LA RAZONABILIDAD Y LA APLICACIÓN DE GENERALIZACIONES}

El argumento principal utilizado por la mayoría de la Corte puede ser leído como una derrota al carácter general de las reglas en manos de la igualdad de trato: es contraria a ese principio la norma que, generalizando, prescribe las mismas consecuencias para sujetos que se encuentran en distintas circunstancias relevantes. Analicemos con más profundidad sus implicancias.

En el derecho moderno las reglas se caracterizan por ser generales y abstractas. Generales en tanto van dirigidas hacia un conjunto indeterminado de personas (a todos los miembros de una categoría) y abstractas puesto que en su enunciación se refieren a clases o tipos de conductas ("matar», "causar un daño»). Al aplicarlas les corresponde a los jueces analizar si los hechos probados en un proceso pueden ser calificados como casos de esas conductas abstractas.

Ellas sirven a diversos fines o propósitos en virtud de los cuales han sido instauradas. Desde esa perspectiva, puede suceder que su aplicación a un caso concreto resulte desajustada en relación con esas u otras razones. Ese desajuste puede darse por la presencia de ciertas propiedades en el caso que hagan que las razones que las justifican no se apliquen al mismo, o bien porque ciertas propiedades hagan concurrir otras razones relevantes que compitan con aquellas que las fundamentan y justifiquen su no aplicación ${ }^{12}$.

12 Recurramos a un conocido ejemplo: si en general se justifica prohibir el ingreso de animales al transporte público porque con eso se evita causar molestias a los pasajeros, la aplicación de esa regla al supuesto de ingreso de un animal pequeño, silente e inofensivo es formalmente correcta pero injustificada desde el plano de las razones que le subyacen, se trata de un caso de no aplicación de las razones que justifican la norma. 
Ese género de problemas, el desacople entre la aplicación de una regla con sus propósitos, es denominado por algunos iusfilósofos como «laguna axiológica». En el nivel de las reglas, además de las lagunas entendidas como vacío legal (ausencia de reglamentación de la cuestión en debate), tendríamos otras de tipo valorativo que se dan cuando las reglas de un sistema jurídico solucionan un caso, pero sin considerar cierta propiedad que debería ser tenida en cuenta de acuerdo con la hipótesis de relevancia que se deriva de los principios (Atienza y Ruiz Manero, 2006: 62).

Para Frederick Schauer (2004) la toma de decisiones basadas en reglas es un procedimiento subóptimo que alcanza sus beneficios solo resignando las aspiraciones a un modelo ideal. ¿A qué se refiere con eso? Pues a que las reglas se apoyan en regularidades empíricas que tienen en cuenta, al prescribir, lo que normalmente ocurre (generalmente los animales en el transporte público causan molestias). Pero lo que regularmente ocurre puede, en algunas ocasiones, no ocurrir. Sin embargo, es preferible, afirma, aceptar esas posibles discordancias, resignar las aspiraciones a obtener un modelo de decisiones que siempre encuentre la mejor decisión para cada caso y optar por la «segunda mejor opción».

Los predicados fácticos de las reglas —a los que les asignan ciertas consecuencias jurídicas - consisten en generalizaciones probabilísticas percibidas como causalmente relevantes respecto de sus «razones subyacentes», es decir, de las metas que con ellas se persiguen o los males que con ellas se buscan evitar (motivos habitualmente implícitos) (Schauer, 2004: 86) ${ }^{13}$. De las infinitas propiedades que los individuos detentamos y que nos diferencian (edad, ingresos, estudios, etcétera), las reglas captan solo algunas en virtud de ciertos juicios de relevancia. Se dirigen a determinados sujetos (identificados por algunas propiedades consideradas relevantes) y conductas entendiendo que, en general, la consecuencia jurídica que se dispone será valiosa para el cumplimiento de las metas que le dan lugar y la justifican. Pero, advierte el autor, que un enunciado sea una generalización implica que no es necesariamente verdadero para todos los casos. Es posible que las generalizaciones resulten inadecuadas bajo la óptica de las razones subyacentes a las reglas (a esto le llama «experiencias recalcitrantes»). Inadecuadas de dos maneras: por incluir casos que no debieran incluirse, lo que

Pero también puede pasar que el animal en cuestión sí moleste, pero sea el lazarillo de uno de los comensales. Estaremos ante un caso de conflicto entre las razones que justifican la prohibición y otras que, para evitar la segregación de quienes poseen discapacidad visual, justifican una excepción.

13 Se trata de una causalidad probabilística o frecuencial en el sentido de que se supone que la incidencia de la consecuencia será mayor en una población que posee la propiedad en cuestión que en una población idéntica en todos los demás aspectos en la cual esa propiedad está ausente (Schauer, 2004: 88). 
denomina «sobreinclusión», o por excluir casos que debieran incluirse, lo que denomina «subinclusión».

Ahora bien, ¿cómo deberían resolverse los casos de desacople entre las reglas y sus razones subyacentes? Se trata, como sugiere Atienza (2018:300), de un problema iusfilosófico bien conocido. El mismo se dirime entre dos grandes posturas: la de los "formalistas» que afirman que las reglas deberían aplicarse sin más y la de quienes sostienen que en su aplicación deberían intervenir también criterios de equidad que permitan resolver los posibles desacoples ${ }^{14}$. Schauer denomina al primero como modelo «atrincherado", y al segundo, como "particularista".

Eso da pie para hacer una primera caracterización iusfilosófica del voto de la mayoría. Detrás de la decisión de inaplicar la regla general que prescribe el pago de impuestos por parte de ciertos jubilados parece haber, de un modo implícito, un posicionamiento sobre los criterios de interpretación jurídica y, más ampliamente, cierta concepción del derecho.

La Corte ha entendido tradicionalmente a la igualdad como la no discriminación, esto es, como la interdicción del trato arbitrario ${ }^{15}$. La Constitución prescribe un trato igual para quienes se encuentran en iguales circunstancias. El modo de determinar el cumplimiento de esa manda es analizar si la distinción en cuestión se apoya en una justificación objetiva y razonable. Si no la tuviera, sería discriminatoria y, por lo tanto, violatoria del pacto constitucional. El juicio de razonabilidad se vuelve determinante para la interpretación en los casos de discriminación ${ }^{16}$.

Ahora bien, analizar la razonabilidad de una regla es una operación que lleva al terreno de la argumentación moral. Exige lograr un equilibrio entre los valores o principios que, siendo relevantes para un caso, tienen exigencias contrapuestas; requiere seleccionar uno de varios equilibrios

14 Como explica Jesús Vega (2014: 132), esta última se trata de una tesis que ya estaba en Aristóteles, quien concebía a la equidad como algo interno al derecho que permite incorporar en su aplicación los valores sustantivos que les preexisten y les dan sentido. La misma no niega las reglas, pero sí su entendimiento puramente formalista, viene a corregir la generalidad de la regla en un caso que, de haberlo conocido, el propio legislador lo hubiera hecho (Vega, 2014: 135-136).

15 Sobre la concepción tradicional en materia de igualdad adoptada por la Corte Suprema argentina véase Saba (2016). También puede consultarse Dieder (2011: caps. III y IV).

16 Por un análisis de las vinculaciones entre los principios de igualdad y de razonabilidad, véase Didier (2011: cap. I.5). La autora sostiene que ambos están estrechamente vinculados, aunque se diferenciarían en que el primero necesita ser aplicado comparativamente y el segundo, en tanto criterio de control de las reglamentaciones a derechos fundamentales, no lo requiere. 
posibles y justificar esa elección (Atienza, 1987). Se trata de un modelo de toma de decisiones tendencialmente "particularista» en tanto admite la posibilidad de derrotar el carácter general de las reglas cuando el equilibrio de las razones relevantes involucradas así lo justificase.

Según el enfoque dado por la mayoría del tribunal, se presentó en el caso un desacople entre la regla impositiva y otras razones de índole constitucional que justifican realizar una excepción a la misma. La actora, además de ser una jubilada con una (relativamente) elevada capacidad adquisitiva, detenta una propiedad (la vulnerabilidad vital) que vuelve irrazonable su inclusión dentro de la categoría de jubilados que tributan el Impuesto a las Ganancias.

Dicho eso, me interesa ahora poner el foco en las razones que invoca para sostener que la persona accionante reviste esa propiedad que justifica un trato distinto. En ese punto argumentación del voto mayoritario presenta severas debilidades.

Al disponer que solo el 10\% de los jubilados (aquellos que más dinero perciben) paguen el Impuesto a las Ganancias, el legislador supone que en general ese conjunto de personas estará en condiciones de afrontar el impuesto sin detrimento de sus otros compromisos vitales. También hace un juicio de valor sobre quiénes y en qué medida es justo que aporten a las arcas públicas.

Para llegar a la conclusión de que esa generalización legislativa es inadecuada o irrazonable para el caso de la actora, la Corte se apoya en otra generalización, también de tipo empírica, según la cual entre los jubilados hay algunos que, por sus condiciones de salud, discapacidad, etcétera, son más vulnerables que otros. Sobre la base de ese enunciado y de aquellos que describen la situación de la actora, el tribunal halla en el caso un trato discriminatorio: se estaría tratando igual a quienes considera desiguales en virtud de ciertas propiedades relevantes.

Los problemas que quiero marcar se encuentran fundamentalmente en la solidez de esa inferencia empírica y en la ponderación que realiza. Para subsumir el caso en la teoría de la igualdad asumida por la Corte, el voto debía justificar que la parte actora, además de ser jubilada y percibir altos ingresos, poseía otra propiedad relevante a los efectos del pago del impuesto que el legislador no contempló. Con fines analíticos podemos dividir ese argumento justificativo en dos premisas. Por un lado, la que afirma (a) la existencia, dentro del universo de jubilados con altos ingresos, de un subgrupo de sujetos poseedores de una propiedad relevante que no está siendo considerada por el legislador pero que, sin embargo, amerita serlo. Por otro lado, aquella que sostiene que (b) la accionante forma parte de ese subgrupo ${ }^{17}$. Las analizaré en ese orden.

17 En el contexto de descubrimiento de esta clase de casos los jueces identifican a partir de sus características cierta propiedad que, pese a ser relevante, ha sido omitida por el legislador. Luego extraen de modo inductivo una regla general según la cual esa 
(a) Sobre la premisa mayor: generalización empirica y ponderación. Como vimos, en el voto se sostiene que el envejecimiento y la discapacidad normalmente obliga a las personas a contar con mayores recursos para no ver comprometido el ejercicio de sus derechos fundamentales y que equiparar a todos los jubilados sin distinguir de acuerdo a su vulnerabilidad omite que el mismo ingreso no impactará de igual manera en un caso que en otro. Eso supone "subcategorizar" "a un universo de contribuyentes que, de acuerdo a una realidad que la Constitución obliga a considerar, se presenta heterogéneo» (cdo. 18).

En otras palabras, se afirma que entre los jubilados es esperable encontrar una proporción más alta de incidencia de los problemas de salud en el presupuesto, es decir, una mayor proporción de gastos en cuestiones de salud en comparación con la categoría más amplia de todos los contribuyentes. Esa premisa, que conecta la vejez y la discapacidad con la mayor necesidad de recursos, constituye una "máxima de la experiencia» ${ }^{18}$ : quienes conocen las vicisitudes del envejecimiento saben que con el paso del tiempo muchas personas comienzan a dedicar cada vez más recursos a los problemas asociados a la salud, lo que se agrava si la persona en cuestión padece de alguna discapacidad. En tanto máxima de la experiencia, su fundamento cognoscitivo depende de la validez y admisibilidad de la generalización que expresa (Taruffo, 2009: 441). En este caso se trata de una máxima que se respalda en la experiencia privada de los jueces, de su conocimiento acerca de la vejez y sus consecuencias. Es una premisa que parece aceptable. Si bien por su importancia para el razonamiento sería deseable acompañarla de respaldos más precisos como la información estadística, consiste en una aserción generalmente aceptada en el ámbito de nuestra cultura social compartida.

Pero lo que es problemático es la conexión de ese argumento con la teoría de la igualdad que adopta el voto: dice que al haber entre los jubilados algunas personas que son más vulnerables que otras, su tratamiento unificado a los fines impositivos es un trato desigual no justificado. Sin embargo, no aporta razones suficientes para sostenerlo.

propiedad es relevante para casos como el analizado. En el contexto de justificación el tribunal debe aplicar esa regla general o «norma adscripta» (Alexy, 1993: 70), extraída a partir de la actividad interpretativa, como premisa mayor de un razonamiento subsuntivo y estar dispuesto, en el futuro, a aplicar el mismo criterio a personas que posean las mismas propiedades relevantes.

18 Una máxima de la experiencia es un juicio hipotético de contenido general que se desprende a partir de la experiencia respecto de sucesos de cierto tipo. Se conforma a través de inducciones ampliativas, es decir, partiendo de hechos individuales para llegar a una regla general que permita explicar y predecir esa clase de hechos (Taruffo, 2009: ap. 27). 
Por un lado, el argumento parece, en cierto aspecto, estar incurriendo en el mismo error que denuncia. Si bien la propiedad que identifica como relevante (y omitida por el legislador) es la de jubilado-vulnerable, el eje sobre el que se monta la observación del tribunal es la «vulnerabilidad vital» de la persona, que es el factor que debería considerar el legislador al momento de confeccionar categorías tributarias. Bajo esa óptica, la propiedad jubiladovulnerable parece ser ella misma «subincluyente» respecto de las razones que justifican su consideración por el tribunal: se trata de un juicio relativo transversal a la propiedad de jubilado. Si bien puede sostenerse que entre las personas jubiladas es esperable encontrar una mayor proporción de sujetos vulnerables que entre las personas que no tienen ese estatus, eso no niega que en ese último grupo haya también sujetos vulnerables (por otras características distintas a la vejez o la discapacidad, o quienes teniéndolas no hubieran accedido a una jubilación). La conclusión a la que llega el voto en este plano general padece del mismo defecto que se le marca al legislador: subcategoriza (o subincluye) a otros sujetos que pese a no estar jubilados tienen la misma propiedad que según la mayoría del tribunal justifica hacer una distinción, la de ser vulnerables.

Eso plantea un problema con una de las reglas fundamentales del discurso práctico general (es decir, uno de sus criterios de corrección material): la regla de la universalidad, según la cual todo hablante que aplique cierto predicado sobre determinado objeto debe estar dispuesto a aplicarlo también a todo otro objeto igual en todos los aspectos relevantes (Alexy, 2007: 266).

Por otra parte, es posible inferir que la universalización de un criterio como el adoptado podría generar importantes consecuencias sobre el sistema tributario. Sin embargo, no se cuenta en el voto con reflexiones sobre esas aristas, es decir, sobre qué implica en términos de financiamiento y de justicia distributiva que los jubilados-vulnerables deban ser especialmente considerados, aun aquellos que están entre quienes más ingresos perciben y cuya condición de vulnerabilidad podría ser hipotéticamente compartida por otros grupos a los que no alcanzaría la regla.

Como propone MacCormick (2018: cap. VI), en los casos difíciles, una vez delimitada la decisión por los principios de universalidad, consistencia y coherencia, la decisión final se debe volcar por aquella opción que resulte mejor en virtud de las consecuencias que traería aparejado el criterio universalmente aplicado a la luz de ciertos fines o valores.

El voto tampoco reflexiona sobre el hecho de que los jubilados que pagan el impuesto sea el 10\% de mayores ingresos. Si bien ese factor no quita que algunos de ellos sean vulnerables en el sentido en que se refiere a ese término el tribunal, se puede suponer a priori que el caudal de sus ingresos les permitiría afrontar sus gastos vitales con mucha mayor solvencia que los jubilados que no pagan el impuesto y que muchas de las personas no jubiladas. El hecho de que, como sostiene la mayoría, el pago del impuesto incida de modo distinto en aquellos jubilados que tienen más gastos vitales no implica necesariamente, 
ni cabe presumir sin ningún otro elemento de convicción, que esas personas no puedan hacer frente a ambos tipos de erogaciones, las impositivas y las correspondientes a sus gastos vitales.

Por último, quedan fuera de análisis importantes consideraciones relativas al ámbito de las políticas sobre el que está decidiendo. Como sugiere Rosenkrantz en su disidencia, la mayoría ha omitido considerar como factores relevantes las demás políticas estatales destinadas precisamente a amortiguar las diferencias detectadas, es decir, a cubrir las contingencias de salud, los medicamentos, etcétera, de las personas jubiladas que así lo requieran. Aceptar la premisa fáctica general en la que se apoya el voto no lleva linealmente a sostener que existe entre los jubilados un desnivel frente a las obligaciones tributarias. Para sostenerlo es necesario incorporar información que permita evaluar el impacto que sobre esa situación pueden tener otras políticas estatales a favor de las personas vulnerables. Tampoco se aportan razones para justificar por qué, aun cuando el desnivel existiera, la solución debería ser adoptada por el legislador en el nivel de las exenciones impositivas (como parece sugerirlo) y no, por ejemplo, con modificaciones al mínimo no imponible, con una baja de la alícuota o, de modo más general, a través de otras políticas sociales que capten la vulnerabilidad vital de las personas desde otro plano.

(b) Sobre la premisa menor: la situación personal de la actora. Ahora bien, aun dejando de lado las críticas recién expuestas, la línea argumentativa del voto mayoritario tiene otro problema de carácter fáctico: ¿se puede sostener que la actora es una jubilada-vulnerable?

Si consideramos que las personas jubiladas con vulnerabilidad vital necesitan afectar mayores recursos a atender cuestiones relacionadas con su salud, y suponemos que el Estado no tiene política alguna para atender esa situación, aún debemos preguntarnos si la accionante detenta esos atributos y, por ende, se justifica excluirla del ámbito de aplicación de la regla. Debemos separar lo que consiste en una proposición referida a una regularidad empírica (entre los jubilados hay una proporción relativamente elevada de personas vulnerables) de una proposición referida a un hecho individual como lo es el estado de salud y económico de la actora.

De una regularidad empírica como la sostenida por el tribunal, según la cual los jubilados normalmente necesitan más recursos para no ver comprometida seriamente su existencia y/o calidad de vida, no se puede inferir con carácter necesario que la actora, por ser jubilada, forma parte del grupo de jubilados-vulnerables que detentan efectivamente esas necesidades. Una regularidad empírica no dice nada, en un principio, sobre un hecho individual como es la situación de la actora. Para alcanzar esa conclusión es preciso incorporar mayor información al razonamiento, mayor incluso a la que se disponía al momento de tomar la decisión. Recordemos que el conjunto de evidencias reunidas era realmente escaso: se conocía la edad de 
la actora, el monto retenido por impuestos y algunos gastos insignificantes en teléfono.

No se disponía, entonces, de ninguna prueba directa de que la actora revestía aquella propiedad relevante que según la mayoría del tribunal el legislador ha omitido, es decir, de su vulnerabilidad vital. Por más que en el caso se considere correcta la premisa normativa general según la cual entre las personas jubiladas de altos ingresos hay algunas que por su vulnerabilidad no se justifica que reciban el mismo trato que las otras, debido a la falta de pruebas sobre el carácter vulnerable de la actora no es posible subsumir su caso individual en esa regla (o «norma adscripta») creada por el tribunal a partir del principio de igualdad. No se puede considerar probado que las circunstancias de la actora califiquen como un caso de los alcanzados por dicho enunciado general.

\section{EL VOTO DISIDENTE Y LAS RAZONES PARA SER DEFERENTES CON EL LEGISLADOR}

La principal línea argumentativa del voto disidente está vinculada, como vimos, con la determinación del rol del Poder Judicial en la interpretación constitucional de las leyes tributarias. Las razones que invoca están mayormente dirigidas a justificar una postura deferente al Poder Legislativo en la materia. Más allá de coincidir con la conclusión a la que arriba, me interesa analizar críticamente la postura que el voto adopta en materia de interpretación y los efectos en términos iusfilosóficos que podría tener su traslación a otras materias distintas a la tributaria.

Partamos de los puntos de encuentro que tienen los dos votos de la sentencia. Ambos coinciden, por un lado, en que dentro del Estado corresponde al Poder Legislativo la atribución de elegir los objetos imponibles, determinar las finalidades de la percepción impositiva y disponer los modos de valuación de los bienes sometidos a gravamen. También en que el Poder Judicial tiene vedado inmiscuirse en el mérito o la conveniencia de esas decisiones, aunque sí esté facultado para controlar que las mismas no vulneren las normas constitucionales o las reglamenten de modo irrazonable. Se tratan de verdaderos tópicos del constitucionalismo vernáculo.

Las discrepancias aparecen a punto de avanzar en la solución del caso concreto llevado a los estrados del tribunal. Si bien en términos generales el Poder Judicial puede controlar el cumplimiento de los imperativos constitucionales en materia impositiva e inaplicar - para un caso concreto- las leyes que no los respetaran, ¿existe mérito en el caso que presenta la actora para ejercer esa función? Los votos toman caminos opuestos en la respuesta a ese interrogante.

La mayoría recurre al principio de igualdad y al juicio de razonabilidad y esa decisión supone asumir ciertas posturas en el terreno iusfilosófico. El voto disidente, en cambio, plantea su oposición a la postura adoptada por la 
mayoría apoyándose en un aspecto previo: discrepa con que los jueces puedan realizar esa clase de interpretaciones en lo que respecta a las leyes tributarias. Si bien invoca argumentos de peso para sostener que el planteo de la accionante debía ser rechazado, una parte importante de sus argumentos se focaliza en justificar una postura interpretativa según la cual el control de razonabilidad de las categorías tributarias estaría vedado o seriamente limitado. El caso de la actora no puede ser acogido no solo porque es justificable que abone el impuesto, sino fundamentalmente porque los jueces no pueden realizar análisis como los que la mayoría realiza.

Si bien el Poder Judicial está habilitado en general para controlar la constitucionalidad de las leyes, en esta clase de casos - afirma Rosenkrantzhay buenas razones para adoptar una postura deferente al legislador. Las decisiones que el Congreso adopte sobre cómo distribuir los recursos nacionales y sobre quiénes y en qué medida es justo que aporten al tesoro no pueden ser suplantadas por la voluntad judicial. Desde esa óptica rechaza - y busca evitar - la posibilidad de que durante la operación interpretativa se permeen los juicios de valor de los jueces sobre cómo deberían gravarse y distribuirse las riquezas dentro del Estado. Debido al nivel de generalidad (o indeterminación) en que están redactadas las normas constitucionales y convencionales que reconocen el derecho a la seguridad social y la obligación del Estado de adoptar medidas de acción positiva a favor de ciertos grupos, descarta que de las mismas pueda inferirse una exención impositiva.

Mi crítica hacia esos aspectos del voto disidente tiene dos ejes. Por un lado, (a) mostrar que una postura de ese tipo no permite explicar y entra en contradicción con una práctica interpretativa asentada en la jurisprudencia del tribunal relevante incluso para cuestiones tributarias. Por otro lado (b) evaluar las implicancias iusfilosóficas de un argumento interpretativo como el que se adopta, en particular las que surgen de su traslación a otras materias distintas a la tributaria.

(a) La postura que adopta el voto disidente sobre la separación de los juicios valorativos en la interpretación no permite explicar y entra en contradicción con una operación que el propio juez disidente admite —en línea con una inalterada línea jurisprudencial del tribunal- como parte de las competencias judiciales (incluso en materia tributaria): el análisis de razonabilidad de las leyes en tanto reglamentaciones de los derechos reconocidos en el texto constitucional. Una cosa sería decir que en el caso concreto, dadas las circunstancias acreditadas y las razones invocadas en el mismo voto, la regla cuestionada resulta razonable, pero otra distinta es afirmar que los jueces no pueden alterar las categorías tributarias creadas por el legislador suplantándolas, a través del desarrollo interpretativo de los principios constitucionales, por ciertas concepciones de la justicia. 
El voto parece presentar, en este punto, una sutil ambigüedad. Podría estar sosteniendo que los jueces tienen vedado reflejar sus juicios de valor personales en las sentencias que dictan, algo que casi nadie querría discutirle. Pero también podría estar sosteniendo una postura escéptica acerca de que las cuestiones prácticas puedan decidirse racionalmente (alejada de cualquier clase de objetivismo moral) y, a la postre, pretender suprimir o limitar los espacios de argumentación moral dentro de las decisiones judiciales para evitar, precisamente, que sean los juicios morales personales de los jueces los que decidan los casos.

En el primero de los sentidos el argumento, si bien conllevaría una significativa adhesión, no tendría demasiada utilidad en la motivación. No permitiría desacreditar la decisión adoptada por la mayoría que, como puede inferirse, no pretende estar consagrando las particulares concepciones de la justicia distributiva de los jueces firmantes sino aquella que resulta correcta para el caso. En el segundo de los sentidos el argumento cumple una función más precisa en la motivación de la disidencia. Le está diciendo a la mayoría que avanzó sobre un terreno, el de las categorías tributarias, que no puede invadir pues les está vedado a los jueces. Sin embargo, tiene como consecuencia vaciar de racionalidad e impedir el juicio que tanto la jurisprudencia asentada de la Corte como el mismo voto disidente reconocen como parte del control de constitucionalidad: el análisis de razonabilidad de las leyes, que, como vimos, implica realizar un equilibrio entre los valores en tensión. El rechazo a la incorporación de la argumentación moral en la interpretación tributaria conlleva a una contradicción que solo puede resolverse prescindiendo de algunas de las premisas: la posibilidad de controlar la razonabilidad de las categorías tributarias o el rechazo a la argumentación moral $^{19}$. Si se acepta, como lo hace el voto disidente en varios pasajes, que la interpretación constitucional tiene cabida en materia tributaria a través del análisis de razonabilidad, el problema sobre la determinación del alcance de los principios contenidos en la Constitución no puede ser resuelto recurriendo solo a interpretaciones semánticas y genéticas (recurso utilizado también en varios pasajes del voto).

(b) El argumento interpretativo del voto disidente, en el segundo de los sentidos identificados antes, está relacionado con al menos dos posturas iusfilosóficas. Parece admitir, en el plano estructural del derecho, la existencia de reglas y de principios, pero otorgándoles a estos últimos una función

19 Una postura escéptica respecto a la existencia de racionalidad en la decisión de las cuestiones prácticas podría sostener como tercera opción la admisión de que en el juicio de razonabilidad existe un espacio de «discrecionalidad en sentido fuerte», en el que los jueces pueden seleccionar entre diversos cursos de acción, concebidos cada uno como permisible por el sistema (véase Lifante, 2002: 417). Pero eso parece ser algo que decididamente el voto pretende evitar. 
inerte en la interpretación. Si en su desarrollo interpretativo no pueden intervenir ciertas concepciones de la justicia, pues se vuelve imposible dotarlos de sentido o, en términos de Alexy (1993: 70), crear a partir de ellos —e invocando argumentos prácticos de tipo general- «normas adscriptas» más precisas en sus condiciones de aplicación que habiliten su aplicación subsuntiva. Al estar la mayoría de los principios constitucionales "radicalmente indeterminados", no podría inferirse nada de ellos.

Esta última afirmación parece tener como respaldo una concepción tendencialmente "formalista» de la interpretación ${ }^{20}$. En efecto, en lo que respecta a los criterios interpretativos lo sostenido en el voto es compatible con otorgar una jerarquía supraordenada y absoluta al derecho de fuente legal. El voto adopta una postura deferente al legislador en cuestiones tributarias no porque les otorgue cierta prevalencia a los argumentos interpretativos semánticos y genéticos (como, por ejemplo, propone Alexy, 2007: 432), sino porque parece colocarlos como los únicos aceptables en la materia ${ }^{21}$, dejando por fuera a las argumentaciones de tipo teleológicas y/o deontológicas (imprescindibles para concretar el juicio de razonabilidad) ${ }^{22}$. Si bien en su entramado argumentativo se encuentra una recurrente referencia a valores, la función de ese recurso mayormente es justificar un minimalismo interpretativo por parte de los jueces. Lo valioso a nivel institucional en materia tributaria sería que los jueces no se inmiscuyan en los juicios de valor implementados por el legislador a través de las leyes que crean, como en el caso, categorías impositivas.

Para defender la deferencia al legislador en materia tributaria el voto aporta, como vimos, razones que atienden fundamentalmente a la distribución de funciones en un Estado constitucional. Al rechazar la intervención del Poder Judicial en la confección de categorías tributarias ha expresado una

20 Formalista en el sentido de que aparenta concebirla como una operación cognoscitiva consistente en descubrir el significado objetivo de un texto o la voluntad subjetiva de su autor, excluyendo la posibilidad de su crítica moral (véase Atienza, 2009: 278-279).

21 En las otras líneas argumentales del voto se puede advertir, además, la invocación de argumentos sistemáticos y el uso de precedentes. Los argumentos genéticos se advierten cuando indaga sobre cuál es el significado que debe dársele a la expresión «integralidad» adoptada por el texto constitucional: es aquel que pretendieron darle los constituyentes. El mismo recurso se repite luego, cuando el juez indaga sobre el sentido de la reforma jubilatoria de 2016: su norte está en lo que los legisladores buscaron con ella.

22 Mientras las argumentaciones interpretativas semántica y genética vinculan a los jueces con el tenor de la ley y la voluntad del legislador, la teleológica abre el campo a la argumentación práctica racional de tipo general (Alexy, 2007: 339-340). 
valoración según la cual esa distribución de las funciones con el Poder Legislativo es la que mejor expresa el modelo de Estado constitucional adoptado por la Constitución nacional.

Advirtiendo eso estamos en condiciones de hacer una primera matización a la idea que parecería postular Rosenkrantz sobre la impermeabilidad de los juicios valorativos de los jueces en la interpretación tributaria. La elección por parte de los jueces (y de los teóricos del derecho) sobre cuál es el modelo de decisión o de interpretación preferible resulta inexorablemente valorativa. Se eligen los modelos de acuerdo a qué valores permiten alcanzar u optimizar, es decir, dependiendo de la ponderación de una serie de razones que concurren y tensionan entre sí: las razones para aplicar uno u otro canon interpretativo. Por ende, no puede sostenerse la prescindencia total de la valoración por parte de los jueces dentro de la argumentación jurídica. Como destaca Lifante Vidal (2018: 219), incluso quienes defienden una posición formalista de la interpretación justifican su opción a través de argumentos valorativos basados, por ejemplo, en el valor de la certeza o de la seguridad jurídica, es decir, en el aspecto autoritativo del derecho.

Presentada esa primera matización, me interesa ahora detenerme en la posibilidad de trasladar el argumento interpretativo que se adopta en el voto disidente a otras materias distintas a la tributaria. Si bien la deferencia al legislador a través del recurso exclusivo a argumentos gramaticales y genéticos podría considerarse justificada en materia tributaria, la traslación de ese criterio al campo general de la interpretación, como podría sugerir una lectura aislada de algunos de los pasajes del voto disidente que he transcripto, presenta mayores problemas.

Para Schauer (2004: cap. VII), como para otros tantos iusfilósofos, un modelo de decisión "basado en reglas», o "atrincherado" a las razones subyacentes de las reglas, debería ser adoptado en general. Si bien desde la perspectiva de la equidad no permite captar — como lo hace su opuestoaquellas diferencias relevantes que hubieran sido ignoradas por el legislador, contribuye a proteger otros valores importantes: aumenta la confianza en el ordenamiento jurídico y la capacidad de predecir los resultados de su aplicación; mejora la eficiencia en la toma de decisiones ya que el decisor no debe examinar todos los rasgos potencialmente relevantes de un caso; evita la comisión de errores en el juicio por parte de los jueces; y contribuye a la estabilidad política y social. El procedimiento más óptimo en general, dice el autor, es el segundo mejor, el que desiste de buscar la decisión óptima en todos los casos individuales.

Otras posturas, en cambio, justifican adoptar un modelo de interpretación que admita dentro de esa operación intelectual a la argumentación práctica general y que permita a los jueces apartarse en algunas circunstancias del sentido literal de los materiales jurídicos.

Robert Alexy (2007: 342) propone darle prevalencia a los argumentos que expresen una vinculación al tenor literal de la ley o a la voluntad del 
legislador histórico. Pero una prevalencia susceptible de ser vencida cuando puedan aducirse otros motivos racionales que concedan prioridad a otra clase de argumentos interpretativos. En cuyo caso, sostiene, juegan un papel decisivo los argumentos prácticos de tipo general, que son los que se encargarán de dirimir si cabe alterar aquella prioridad concedida prima facie. El peso de los argumentos para apoyar ciertos cánones interpretativos se determinaría de acuerdo a las reglas de la ponderación, desarrolladas con referencia a determinados contextos de interpretación y determinados sectores del derecho. Para saber cuándo hay argumentos racionales para abandonar los criterios gramatical y genético hay que tomar en cuenta «todos los argumentos que sea posible proponer y que puedan incluirse por su forma entre los cánones de interpretación» (Alexy, 2007: 344).

Las divergencias entre ambas clases de posturas pueden ser vistas como respuestas distintas a la tensión inherente al derecho entre sus aspectos autoritativo y valorativo. Mientras las posturas formalistas privilegian el primero, posturas como las constructivistas — defendidas por autores como Dworkin, Nino, Alexy, MacCormick o Atienza - hacen primar su aspecto valorativo, esto es, al conjunto de valores expresados en los principios constitucionales (Lifante Vidal, 2018: 66). A diferencia de las posiciones formalistas, estas últimas aspiran a expresar la mejor versión del derecho en cada acto de aplicación. Si bien disminuyen la predecibilidad de los resultados de la aplicación del derecho, lo que suele denominarse «seguridad jurídica», permiten optimizar mejor la consecución de los objetivos y valores que la práctica jurídica pretende desarrollar.

La elección del modelo de interpretación depende de la idea que se adopte sobre la función del derecho en un Estado. Si debería servir solo para asegurar el orden o, también, para cumplir con otros fines y valores como la vigencia de ciertos principios ${ }^{23}$.

Esa respuesta, por otra parte, debe darse de modo situado. No es lo mismo asegurar o conservar el statu quo en contextos donde el mismo resulta aceptable que hacerlo en otros donde busca ser transformado. En los países latinoamericanos podemos ver que el desarrollo contemporáneo del constitucionalismo ha tenido una impronta transformadora: con la modificación de los textos constitucionales - que incluye, entre otras aristas, una considerable expansión de sus partes dogmáticas - se ha buscado modificar de algún modo una serie de condiciones políticas, económicas y sociales consideradas inaceptables.

La pregunta sobre cómo debe ser interpretado el derecho es un interrogante abierto y en permanente debate en el campo iusfilosófico. Su respuesta

23 El propio Schauer (2004: 217 y ss.) reconoce el carácter conservador del statu quo en la posición «basada en reglas» que defiende. Sin embargo, agrega que el mismo se puede considerar una virtud siempre en relación con un contexto social y político específico, de lo deseable que resulte el estado de cosas a estabilizar. 
supone la asunción de cierta concepción del derecho (ej., positivista o postpositivista) que suele interactuar con alguna teoría de la ética (ej., cognoscitivistas y no cognoscitivistas) y a su vez impacta en —y se retroalimenta de — la teoría política: el modo de concebir el derecho se encuentra atado al modo en que se reparte el poder hacia el interior de los Estados típicamente entre los órganos que se encargan de crear sus fuentes autoritativas y aquellos que se encargan de resolver las controversias jurídicas entre de los ciudadanos entre sí o frente al Estado ${ }^{24}$. La manera de entender la interpretación jurídica es una célula de una serie de posicionamientos teóricos éticos y políticos que - de modo expreso o veladamente- dan sentido a las posturas sobre qué cánones interpretativos es preferible utilizar. Cuando indagamos sobre cómo interpretar en cierto punto también nos estamos preguntando qué clase de valores queremos que nuestros Estados optimicen.

Ahora volvamos al voto disidente. Dado que algunas de las razones dadas por Rosenkrantz para justificar la deferencia al legislador en materia tributaria podrían ser leídas, de modo aislado y quizá sacadas de contexto, como un alegato a favor del formalismo en la interpretación jurídica, el panorama reseñado nos permite advertir que los motivos que justifican esa deferencia en el terreno impositivo no pueden ser linealmente trasladados al campo general de la interpretación. $\mathrm{O}$ si esa fuera la intención debería poder explicarse por qué es preferible un modelo de Estado de derecho donde en la aplicación de las normas prima exclusivamente el aspecto formal y queda relegada la dimensión valorativa o axiológica de la empresa jurídica. Es decir, por qué preferir un modelo de decisión donde se les dé una prevalencia general a los valores instrumentales de la seguridad y el orden formal por sobre los vinculados con la justicia material.

En resumen, puede decirse que si bien las razones dadas en el voto disidente para la deferencia al legislador son atendibles mientras se mantienen encapsuladas en la cuestión tributaria, las mismas resultan problemáticas y, en todo caso, necesitan ser complementadas si se busca trasladarlas al campo general de la interpretación, sopesando las consecuencias que tendría asumir una posición de esas características para el ideal del Estado de derecho.

\section{CONCLUSIONES}

La sentencia analizada ofrece un contrapunto conceptualmente rico en torno a la interpretación jurídica y la función del Poder Judicial en materia

24 En palabras de MacCormick (2010: 77), «la teoría de la interpretación como tema intrínseco al estudio de la argumentación práctica nos conduce necesariamente a las aguas más profundas de la normativa constitucional y la teoría política; es decir, a la libre argumentación práctica aplicada a las instituciones políticas y jurídicas básicas». 
impositiva y más allá. En ella se ha impuesto cierta delimitación de las atribuciones jurisdiccionales sobre las facultades del Congreso de imponer tributos que resulta favorable a las competencias de los jueces encargados de aplicar la Constitución que, en Argentina, son todos.

Entrando en el análisis de los argumentos invocados por los dos votos que la componen, hemos visto que la mayoría del tribunal recurrió a la aplicación del principio de igualdad. Lo hizo, sin embargo, con justificaciones sumamente frágiles en general y en su aplicación a las circunstancias concretas del caso que le tocaba decidir. Si bien la legislación impositiva argentina impone el impuesto a las ganancias a los haberes jubilatorios más acaudalados del sistema previsional, la mayoría entendió que existía una propiedad relevante, la vulnerabilidad vital de las personas, que el legislador no estaba contemplando, debiendo hacerlo. En el análisis del voto he identificado dos premisas de su razonamiento justificativo. Una premisa indica que existe, dentro del universo de jubilados con altos ingresos, un subgrupo de sujetos poseedores de una propiedad relevante, la vulnerabilidad vital, que no está siendo considerada por el legislador pero que, sin embargo, amerita serlo. Se trata, sostuve, de una generalización que, como máxima de la experiencia, podría considerarse avalada. Sin embargo, la falla radica en considerar que no se justifica darle a todo el grupo de jubilados el mismo trato. Al sostenerlo el voto incurre en el mismo error que denuncia, la subinclusión de otras personas que, sin ser jubiladas, son también vulnerables y podrían aspirar a beneficiarse de la misma exención que en el fallo se está acordando. Además, tampoco tiene en cuenta los impactos de la decisión sobre el sistema tributario ni que al abonar el impuesto los jubilados que más dinero perciben es posible que puedan absorber tanto ese tributo como los gastos propios de la edad. La otra premisa que se puede analizar tiene que ver con la conexión entre la anterior y las circunstancias del caso objeto de decisión. Sostener que en general los jubilados son sujetos vulnerables no habilita a concluir, sin más, que cada jubilado lo es. Eso es lo que hace el voto analizado al asumir esa condición en la accionante sin otros elementos de prueba relevantes que lo ratificasen. De una regularidad empírica según la cual los jubilados normalmente necesitan más recursos no se puede inferir con carácter necesario que la actora estuviera en esas circunstancias.

El voto disidente aporta buenas razones para rechazar el planteo de la actora, pero trae aparejados otros problemas desde la perspectiva iusfilosófica. $\mathrm{Al}$ pretender suprimir o limitar los espacios de argumentación moral dentro de las decisiones judiciales, parece vaciar de contenido a una práctica interpretativa asentada en la jurisprudencia del tribunal incluso para la materia impositiva: el análisis de razonabilidad de las leyes en tanto reglamentaciones de los derechos constitucionales. Analizar si una regla establece una categorización razonable implica realizar un equilibrio entre los valores o principios relevantes para el caso que tensionan entre sí y seleccionar uno entre los posibles equilibrios (Atienza, 1987). ¿Cómo cumplir con esa función prescindiendo 
de la argumentación sobre valores? Por otra parte, puede decirse que el argumento interpretativo del voto disidente está relacionado con al menos dos posturas iusfilosóficas. Parece admitir, en el plano estructural del derecho, la existencia de reglas y de principios, pero otorgándoles a estos últimos una función inerte en la interpretación. Las razones para la deferencia al legislador invocadas pueden tener sentido y resultar atendibles con referencia a la cuestión tributaria. Sin embargo, su traslación al campo general de la interpretación requiere de un ejercicio más acabado de argumentación que sopese las consecuencias que tendría asumir una posición de ese tipo para el ideal del Estado de derecho. No puede perderse de vista que la elección por parte de los jueces (y de los teóricos del derecho) sobre cuál es el modelo de decisión o de interpretación preferible resulta inexorablemente valorativa. Se eligen los modelos de acuerdo a qué valores permiten alcanzar u optimizar. Algunas posturas otorgan mayor previsibilidad, pero también muchas veces resultados vacuos, mientras que otras resultan menos previsibles en general, pero permiten desarrollar en mayor medida los principios jurídicos relevantes. Es valioso, además, pensar estas cuestiones de modo situado, ya que no es lo mismo asegurar o conservar el statu quo en contextos donde el mismo resulta aceptable que hacerlo en otros donde el mismo busca ser transformado.

\section{Bibliografía}

Alexy, R. (1993). Teoria de los derechos fundamentales. Madrid: Centro de Estudios Políticos y Constitucionales.

- (2007). Teoría de la argumentación jurídica. Lima: Palestra.

Atienza, M. (1987). Por una razonable definición de «razonable». Doxa: Cuadernos de Filosofia del Derecho, 4, 189-200. Disponible en: https://doi.org/10.14198/ DOXA1987.4.13.

- (2009). El sentido del Derecho. Barcelona: Ariel.

- (2018). Curso de Argumentación Jurídica. Madrid: Trotta.

Atienza, M. y Ruiz Manero, J. (2006). Ilícitos atípicos. Madrid: Trotta.

Didier, Ma. M. (2011). El principio de igualdad en las normas jurídicas. Estudio de la doctrina de la Corte Suprema de Argentina y su vinculación con los estándares de constitucionalidad de la jurisprudencia de la Corte Suprema de los Estados Unidos. Buenos Aires: Marcial Pons.

Lifante Vidal, I. (2002). Dos conceptos de discrecionalidad jurídica. Doxa: Cuadernos de Filosofia del Derecho, 25, 413-439. Disponible en: https://doi.org/10.14198/ DOXA2002.25.12.

- (2018). Argumentación e interpretación jurídica. Escepticismo, intencionalismo y constructivismo. Valencia: Tirant Lo Blanch. 
MacCormick, N. (2010). Argumentación e interpretación en el Derecho. Doxa: Cuadernos de Filosofía del Derecho, 33, 65-78. Disponible en: https://doi. org/10.14198/DOXA2010.33.04.

- (2018). Razonamiento jurídico y Teoría del Derecho. Lima: Palestra.

Saba, R. (2016). Más allá de la igualdad formal ante la ley: ¿qué les debe el Estado a los grupos desaventajados? Buenos Aires: Siglo XXI Editores.

Schauer, F. (2004). Las reglas en juego. Un examen filosófico de la toma de decisiones basadas en reglas en el derecho y en la vida cotidiana. Madrid: Marcial Pons.

Taruffo, M. (2009). Páginas sobre justicia civil. Madrid: Marcial Pons.

Vega, J. (2014). La actualidad de la equidad de Aristóteles. Doce tesis antiformalistas sobre el derecho y la función judicial. Cuadernos Electrónicos de Filosofia del Derecho, 29, 113-144. Disponible en: https://doi.org/10.11117/19824564.07.03. 